\title{
Interrelationship of hepatitis $C$ virus genotypes with patient characteristics in Bahrain
}

This article was published in the following Dove Press journal:

Hepatic Medicine: Evidence and Research

I March 2017

Number of times this article has been viewed

\section{Maheeba A Abdulla' \\ Eman A Murad' \\ Hend A Aljenaidi' \\ Duha R Aljowder' \\ Omar IK Aljeeran' \\ Eman Farid ${ }^{2}$ \\ Jehad R Al Qamish ${ }^{3}$}

'Department of Internal Medicine, ${ }^{2}$ Department of Pathology, Salmaniya Medical Complex, ${ }^{3}$ Department of Internal Medicine, Ibn Al Nafees Hospital, Manama, Bahrain
Correspondence: Maheeba AM Abdulla Salmaniya Medical Complex, P.O. Box 12, Manama, Bahrain

Email amaheeba@hotmail.com
Aim: Hepatitis $\mathrm{C}$ virus (HCV) shows genotype-based variation in prevalence across geographical regions. This study was conducted to understand the clinical interrelationship of HCV genotypes with patient characteristics.

Methods: Medical records of 122 patients positive for HCV RNA test collected during 2013 and 2014 were included for analysis. Only adults were included in the study. HCV RNA extraction and genotyping was done as part of the routine diagnostic requirements. The association of continuous and categorical variables with genotypes was analyzed through analysis of variance and chi-square tests, respectively.

Results: Of the 122 patients selected, 103 were Bahrainis, 18 non-Bahrainis, and 1 was unregistered. Genotype 1 was the predominant (53\%) one, followed by types $3(23 \%)$ and $4(20 \%)$. Classical symptoms, clinical signs, liver function test, and ultrasonographic results were recorded. Cirrhosis and ascites showed significant variation across genotypes. Although alanine transaminase, total bilirubin, and albumin levels were increased, gamma-glutamyltransferase and alkaline phosphatase levels were normal. About $12 \%$ of the subjects were alcohol users, $4 \%$ were positive for HIV infection and $2.4 \%$ were positive for hepatitis B virus infection. The circulating HCV RNA load was at medium-level in the study cohort and showed significant association with the HCV genotypes and subtypes. Patients with genotype 1a had 6 times more load than patients with type $4(P<0.05)$. Conclusion: This study reconfirmed the incidence and distribution of different genotypes in Bahrain population, and delineated the relationship of HCV RNA viral load with the severity of liver disease in our cohort.

Keywords: hepatitis C virus, hepatitis, Bahrain

\section{Introduction}

Hepatitis $\mathrm{C}$ virus (HCV) is one of the primary causes of chronic liver disease across the world. ${ }^{1}$ As per the World Health Organization, this bloodborne pathogen is estimated to infect $\sim 3 \%$ of the population. ${ }^{2}$ The high-level of incidence of HCV makes it one of the few diseases with great economic implications. This infection is recognized as a globally important disease requiring active interventions and extensive measures for treatment and prevention. Numerous long-term studies have showed that $\sim 80 \%$ of acute infections progress to chronic phase, with $10 \%-20 \%$ of these further ending up with life-threatening conditions, such as hepatocellular carcinoma and cirrhosis. ${ }^{3-5}$ The prevalence of $\mathrm{HCV}$ is the highest in Asian and African subcontinents, whereas European, North American, and Australian regions have the lowest incidence. Middle Eastern regions have a low $(<1 \%)$ to high $(>2.9 \%)$ incidence of $\mathrm{HCV}$, with Bahrain estimated to have a low incidence. ${ }^{6}$ 
HCV (genus: Hepacivirus; family: Flaviviridae) is a single strand positive sense RNA virus made of 9400 base pairs genome, ${ }^{7,8}$ encoding $\sim 3000$ amino acids. Six genotypes (1-6) of HCV have been identified, which ${ }^{9}$ further have large number of subtypes. Epidemiological studies of HCV are largely based on genotyping as there is a wide geographical variation in the genotypic distribution. ${ }^{10,11}$ Genotypes $1-3$ frequently occur in Japan, North America, and Europe; genotype 4 in Middle East, Egypt, and Central Africa; genotype 5 in South Africa; and genotype 6 in Asia. These genotypes harbor $\sim 31 \%-34 \%$ sequence variation, resulting in $\sim 30 \%$ variation in their amino acid products. This variation underlies the pathogenicity and other characteristics of HCV virus. Hence, it is essential to characterize the genotype specific incidence and understand the interrelationship of these genotypes with patient-related factors to employ appropriate and effective preventive and treatment measures. For instance, compared to genotypes 2 and 3, genotypes 1 and 4 are less susceptible to ribavirin and interferon therapy. ${ }^{12}$

In our previous study, which was a first attempt from Bahrain, we showed that genotype 1 was predominant $(36.6 \%)$ in the patients with hepatitis $\mathrm{C}$, followed by type 3 (18.6\%), type $4(9.8 \%)$, and type $2(5.5 \%) .{ }^{13}$ Interestingly, contrast to the established predominance of genotype 4 in Middle Eastern regions including Bahrain, ${ }^{14}$ genotype 1 was most common in our study cohort. Hence, in continuation of our previous work, this study was aimed at finding interrelationship of the genotypes with patient characteristics in the cohorts attending our medical center.

\section{Materials and methods Study population}

This study was conducted at Medical Department of Salmaniya Medical Complex in the Kingdom of Bahrain. Medical records of 122 patients positive for HCV RNA test collected between 2013 and 2014 were included. In these subjects, serum was obtained from blood collected by venipuncture and stored at $-20^{\circ} \mathrm{C}$ as part of routine diagnosis. For this study, chronic HCV infection was defined as inflammation of the liver caused by HCV lasting $\geq 6$. This study was reviewed and approved by the Salmaniya Medical Complex Institutional Review Board. Due to the retrospective nature of the study, written informed consent was not obtained. The patient data were maintained securely in the hospital records without open sharing. Only adult patients with positive HCV RNA and available medical records were included in the study; children were excluded. Real-time ultrasound was used to evaluate for cirrhosis by demonstrating typical morphological characteristics in contour, texture, and portal collaterals of the liver.

\section{HCV RNA assay and genotyping}

Fully automated Abbott m2000 machine was used along with the manufacturer supplied reagent kits for HCV genotyping and consolidated HCV viral load estimation (Abbott Molecular, Abbott Park, IL, USA). This assay quantifies HCV RNA using in vitro reverse transcription-polymerase chain reaction (PCR) method. This assay has a sensitivity of $12 \mathrm{IU} / \mathrm{mL}$ for $0.5 \mathrm{~mL}$ and $30 \mathrm{IU} / \mathrm{mL}$ for $0.2 \mathrm{~mL}$ sample volume with a detection range of $12 \mathrm{IU} / \mathrm{mL}(\log 1.08 \mathrm{IU} / \mathrm{mL})$ to $100 \mathrm{million} \mathrm{IU} /$ $\mathrm{mL}(\log 8.0 \mathrm{IU} / \mathrm{mL})$. This assay detects genotypes $1-6$ with a specificity of $\geq 99.5 \%$. Genotyping was done using standard oligonucleotide specific primers through PCR as described in our earlier report. ${ }^{13}$

\section{Statistical analyses}

The statistical tests were chosen to understand the interrelationship of the HCV genotypes with patient characteristics. All the data were expressed as mean \pm standard deviation. Association of continuous variables with genotypes was analyzed through analysis of variance with post hoc evaluation for significant results. Kruskal-Wallis nonparametric test was used for non-normally distributed data. Categorical variables were analyzed through chi-square test. All the tests were performed through Statistical Package for Social Sciences, version 16 (SPSS Inc., Chicago, IL, USA). ${ }^{15}$

\section{Results}

Of the 122 patients selected, 103 were Bahrainis, 18 nonBahrainis, and 1 was unregistered. Just more than half of the subjects (57\%) were males (Table 1). Genotype 1 was most common (53\%), followed by type 3 (23\%) and type $4(20 \%)$. Only 1 patient each had genotypes 2 and 5. Subtyping, further, showed that type 1a was the predominant $(30.33 \%)$ one, followed by $1 \mathrm{~b}(22.13 \%), 4$ (18.85\%), and 3 (18.03\%), with other types detected in very low frequency (Table 2). The average age of the cohort was 52 years.

The patients recorded 6 primary symptoms at the time of clinical history taking. Abdominal pain (4.1\%) was the most common symptom, followed by bleeding (3.4\%), fatigue $(3.3 \%)$, and jaundice (2.5\%). None of these symptoms were dependent on specific genotypes or subtypes (all $P>0.05$ ).

On clinical examination, hepatomegaly was the most common sign (4.9\%), followed by splenomegaly (4\%), ascites $(2.5 \%)$, and jaundice $(0.8 \%)$. None of the patients had encephalopathy. Both hepatomegaly and splenomegaly were 
Table I Study cohort characteristics

\begin{tabular}{lllllll}
\hline Variables & Genotype & & & \\
\cline { 2 - 7 } & $\mathbf{I}$ & $\mathbf{2}$ & $\mathbf{3}$ & $\mathbf{4}$ & $\mathbf{5}$ & Overall \\
\hline $\mathrm{N}(\%)$ & $53(68)$ & $23(\mathrm{I})$ & $28(24)$ & $<1(\mathrm{I})$ & 122 \\
Gender (male, \%) & 57 & 0 & $6 I$ & 50 & 0 & 57 \\
Age (years, mean \pm SD) & $53.08 \pm 10.74$ & 48 & $49.03 \pm 8.87$ & $50.41 \pm 11.82$ & 76 & $51.77 \pm 10.77$ \\
\hline
\end{tabular}

Abbreviation: SD, standard deviation.

Table 2 Hepatitis $C$ virus subtypes frequency in the study cohorts

\begin{tabular}{|c|c|c|c|c|c|c|c|c|c|c|c|}
\hline \multirow[t]{2}{*}{ Variable } & \multicolumn{11}{|c|}{ Genotype } \\
\hline & $\mathrm{I}$ & 2 & 3 & 4 & Ia & Ib & $3 a$ & $3 b$ & $4 a$ & $5 a$ & Overall \\
\hline $\bar{N}(\%)$ & $3.28(4)$ & $0.88(I)$ & $18.03(22)$ & $18.85(23)$ & $30.33(37)$ & $22.13(27)$ & $4.10(5)$ & $0.88(\mathrm{I})$ & $0.88(I)$ & $0.88(\mathrm{I})$ & 122 \\
\hline
\end{tabular}

A

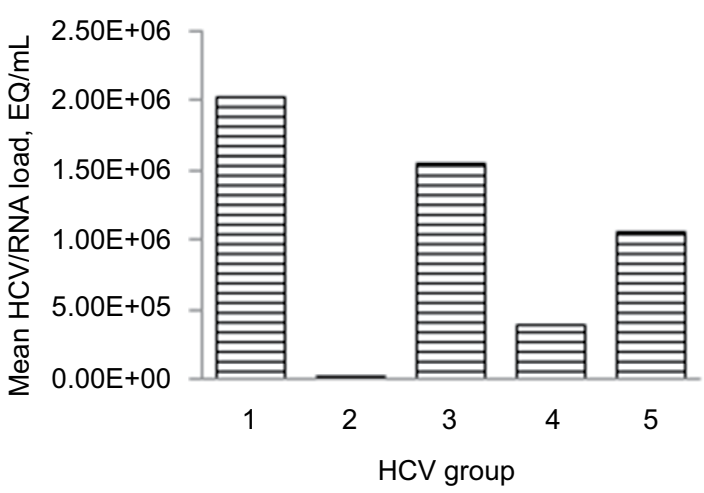

Figure I Variation of HCV RNA load across genotypes (A) and subtypes (B) Abbreviation: $\mathrm{HCV}$, hepatitis $\mathrm{C}$ virus.

present more frequently in patients with genotype 3 (14.28\%; $P=0.032$ and $10.71 \% ; P=0.028$, respectively).

Evaluation for most concomitant and risk factors revealed that $12.2 \%$ of the subjects were alcohol users, with $4 \%$ positive for human immunodeficiency virus infection and $2.4 \%$ were positive for hepatitis B virus infection. There was, however, no correlation between the above risk factor with any of the genotypes.

Ultrasonography of the hepatic and portal structures demonstrated changes suggestive of cirrhosis in $25.2 \%$ of the patients. Hepatomegaly was reported in $23.5 \%$, splenomegaly in $12.5 \%$, portal hypertensive changes in $6.7 \%$, and ascites in $3.8 \%$. Patients with genotypes 1a and $5 \mathrm{a}$ had a higher rate of ascites and cirrhotic changes when compared to those with other genotypes $\left(X^{2}=38.29 ; P=0.000\right.$ and 23.83; $P=0.005$, respectively). Hepatomegaly $\left(X^{2}=9.20 ; P=0.419\right)$, splenomegaly $\left(X^{2}=14.10 ; P=0.119\right)$, and portal hypertension $\left(X^{2}=4.74 ; P=0.856\right)$ did not show statistical significance across genotypes.

The mean alanine amino transferase $(114.26 \pm 41.45 \mathrm{U} / \mathrm{L}$; $\mathrm{n}=116)$, alkaline phosphatase $(114.24 \pm 45.86 \mathrm{U} / \mathrm{L} ; \mathrm{n}=116)$, and gamma-glutamyl-transpeptidase concentration
B

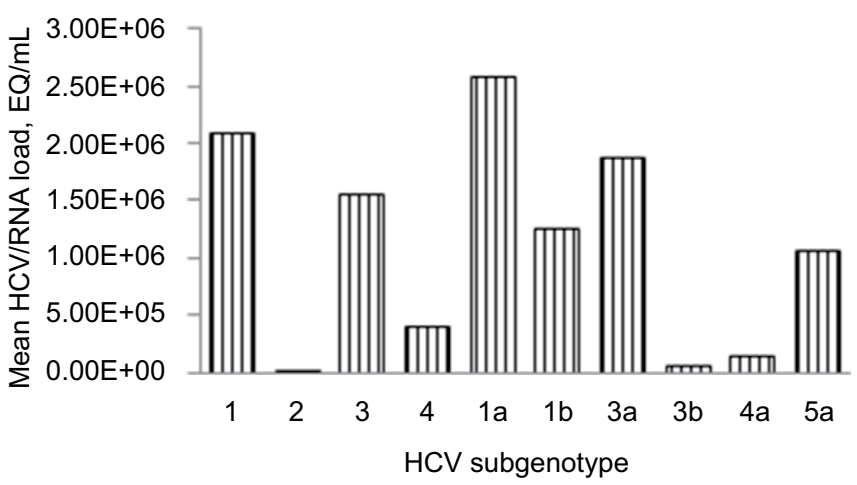

(134.44 $\pm 120.15 \mathrm{U} / \mathrm{L} ; \mathrm{n}=116)$ were above the normal range; however, the mean of both albumin $(37.38 \pm 5.22 \mathrm{~g} / \mathrm{L} ; \mathrm{n}=116)$ and total bilirubin $(14.79 \pm 2.05 \mathrm{mg} / \mathrm{dL} ; \mathrm{n}=116)$ were normal. No statistical difference was detected across the different genotypes.

The average HCV RNA load in the circulating blood of the study cohorts was $1.2 \times 10^{6}(n=122)$. The HCV RNA data were not normally distributed (Anderson-Darling test; $P<0.01)$. The HCV RNA viral load showed a statistically significant variation across the genotypes $(\mathrm{H}=12.89 ; P=0.002$; Figure 1A), with a mean rank of 67 for genotype 1, 63 for genotype 3 , and 38 for genotype 4 . Similarly, further analysis also showed that the HCV RNA load varied significantly across the subtypes $(\mathrm{H}=26.50 ; P=0.000$; Figure $1 \mathrm{~B})$, with a mean rank of 58 for genotype 3, 36 for type 4, 76 for type 1a, 46 for type $1 b$, and 76 for type $3 a$.

\section{Discussion}

There have been limited studies on the prevalence of HCV in the Kingdom of Bahrain. An earlier study had showed that the overall prevalence of $\mathrm{HCV}$ was $0.3 \%$ in normal population; ${ }^{13}$ however, this was contradicted by a more recent study that 
reported a much higher prevalence at a rate of $3.6 \% .{ }^{16}$ The Ministry of Health in Bahrain has recently produced a report that put the prevalence of $\mathrm{HCV}$ at $0.99 \% .{ }^{17}$ The genotype distribution in earlier studies was similar to our findings, ${ }^{13}$ and those reported by Janahi et al. ${ }^{18}$ The risk factor for transmission remains unknown in $40 \%$ of patients; however, blood transfusion was a major risk factor in the cohorts that we reported in an earlier study. ${ }^{13}$

One-third of the study cohort were infected with genotype $1 \mathrm{a}$, followed by $1 \mathrm{~b}(22 \%), 4(19 \%)$, and $3(18 \%)$. While the prevalence pattern for genotypes $1 \mathrm{a}$ and $1 \mathrm{~b}$ is concurrent with previous reports for this region, ${ }^{13,14}$ the genotypes 3 and 4 showed a difference. Our previous report had recorded $26 \%$ and $15 \%$ each of genotypes 3 and 4 . However, in this study these genotypes were detected to have similar occurrence.

The symptoms, clinical signs, concomitant risk factors, and the liver function changes in the study cohort were found to follow the established pattern reported by numerous earlier studies. ${ }^{19}$ No variation was recorded across genotypes. A very important and interesting finding in this study was the significant variation of cirrhosis and ascites rates across the genotypes, unlike the other recorded changes, such as hepatomegaly or splenomegaly. Although this is a very interesting finding, the small sample size of this study provides low-level of confidence for generalization of this finding.

The main changes in the liver function tests noted in this cohort of patients were of the alanine transaminase (ALT), total bilirubin, and gamma-glutamyltransferase (GGT) raised levels. The bilirubin and albumin levels, however, were within the normal range. The findings are not dissimilar to those reported in other studies. ${ }^{20}$ There were no significant statistical differences in the liver function abnormalities among the different genotypes. It is not uncommon to find disproportionate changes in liver function parameters even though the HCV infection and hepatitis are established. Earlier studies have also encountered this important laboratory picture where not all the patients, even after chronic infection with HCV, showed abnormal levels of ALT. ${ }^{21,22}$ Silini et al showed that in a cohort of 341 subjects chronically infected with HCV, $70 \%$ of patients had normal ALT. ${ }^{21}$ Furthermore, these subjects also did not show ALT derangement although chronic hepatitis was confirmed histologically. These findings are important and suggest that the severity or presence of HCV infection cannot be solely based on the liver function tests. ${ }^{22}$

The circulating HCV RNA load showed highly significant variation across genotypes. Those with genotypes 1 and 4 had on average higher levels of HCV RNA load, unlike the patients of genotypes 2 and $3 \mathrm{~b}$ where significant lower levels were detected in the blood. The significance of both viral genotype and load in relation to the severity of liver disease is unclear. Studies have demonstrated normality of both ALT and liver histology in a background of high viral load. ${ }^{23-25}$ Earlier studies found HCV genotype to be associated with a more severe liver disease, including a higher frequency of cirrhosis and hepatocellular carcinoma. However, many of these studies did not control for important confounding factors, such as age, source, and duration of infection. In studies with adjustment for these variables, the association between genotype $1 \mathrm{~b}$ and a more severe liver disease has not been found. ${ }^{23}$ Further studies are warranted in order to better delineate the relationship of the genotype on the outcome of HCV-related liver disease.

One interesting application to HCV RNA quantification is demonstrated in a recent study that looked at shortening HCV treatment duration. The combination of lidepasvir/ sofosbuvir was found to be effective if given for 8 weeks rather than 12 weeks to $\mathrm{HCV}$ genotype 1 patients who had a viral load of $<6,000,000 \mathrm{IU} / \mathrm{mL}^{26}$

\section{Conclusion}

This study has highlighted the pattern of hepatitis $\mathrm{C}$ in Bahrain population. It reconfirmed the incidence and distribution of different genotypes. The study has also delineated the relationship of HCV RNA viral load with the severity of liver disease. This study was conducted to understand the clinical interrelationship of HCV genotypes with patient characteristics in 122 Bahraini adult patients positive for HCV RNA. Genotype 1 was the predominant (53\%) one, followed by types $3(23 \%)$ and $4(20 \%)$. Cirrhosis and ascites showed significant variation across genotypes. Although ALT, total bilirubin, and albumin levels were increased, GGT and ALP levels were normal. About $12 \%$ of the subjects were alcohol users, $4 \%$ were positive for HIV infection, and $2.4 \%$ were positive for hepatitis B virus infection. The circulating HCV RNA load was at medium-level in the study cohort and showed significant association with the HCV genotypes and subtypes. Patients with genotype 1 a had 6 times more load than patients with type $4(P<0.05)$. This study reconfirmed the incidence and distribution of different genotypes in Bahrain population, and delineated the relationship of HCV RNA viral load with the severity of liver disease in our cohort.

\section{Acknowledgment}

We would like to thank Research-Medics for their editorial assistance in the preparation of this manuscript.

\section{Disclosure}

The authors report no conflicts of interest in this work. 


\section{References}

1. Lavanchy D. The global burden of hepatitis C. Liver Int. 2009;29(Suppl 1): $74-81$.

2. McHutchison JG, Bacon BR. Hepatitis C: a 20-year debt comes due. Am J Manag Care. 2004;10(2 Suppl):S20.

3. Zhou S, Zhao Y, He Y, et al. Hepatitis B and hepatitis C seroprevalence in children receiving antiretroviral therapy for human immunodeficiency virus-1 infection in China, 2005-2009. J Acquir Immune Defic Syndr. 2010;54(2):191-196.

4. Kiyosawa K, Sodeyama T, Tanaka E, et al. Interrelationship of blood transfusion, non-A, non-B hepatitis and hepatocellular carcinoma: analysis by detection of antibody to hepatitis C virus. Hepatology. 1990; 12(4 Pt 1):671-675.

5. Lavanchy D. Evolving epidemiology of hepatitis C virus. Clin Microbiol Infect. 2011;17(2):107-115.

6. Global Burden of Hepatitis C Working Group. Global burden of disease (GBD) for hepatitis C. J Clin Pharmacol. 2004;44(1):20-29.

7. Suzuki T, Ishii K, Aizaki H, Wakita T. Hepatitis C viral life cycle. $A d v$ Drug Deliv Rev. 2007;59(12):1200-1212.

8. Ishii K, Tanaka Y, Yap CC, Aizaki H, Matsuura Y, Miyamura T. Expression of hepatitis C virus NS5B protein: characterization of its RNA polymerase activity and RNA binding. Hepatology. 1999;29(4): 1227-1235.

9. Simmonds P, Bukh J, Combet C, et al. Consensus proposals for a unified system of nomenclature of hepatitis C virus genotypes. Hepatology. 2005;42(4):962-973.

10. Cantaloube JF, Laperche S, Gallian P, Bouchardeau F, de Lamballerie X, de Micco P. Analysis of the 5 ' noncoding region versus the NS5b region in genotyping hepatitis $\mathrm{C}$ virus isolates from blood donors in France. J Clin Microbiol. 2006;44(6):2051-2056.

11. Mora MV, Romano CM, Gomes-Gouvea MS, Gutierrez MF, Carrilho FJ, Pinho JR. Molecular characterization, distribution, and dynamics of hepatitis $\mathrm{C}$ virus genotypes in blood donors in Colombia. J Med Virol. 2010;82(11):1889-1898.

12. Pawlotsky JM, Tsakiris L, Roudot-Thoraval F, et al. Relationship between hepatitis $\mathrm{C}$ virus genotypes and sources of infection in patients with chronic hepatitis C. J Infect Dis. 1995;171(6):1607-1610.
13. Abdulla MAM, Qamish JRA. Hepatitis $C$ virus infection: a single center experience. Bahrain Med Bullet. 2008;30(1):1-9.

14. Qadi AA, Tamim H, Ameen G, et al. Hepatitis B and hepatitis C virus prevalence among dialysis patients in Bahrain and Saudi Arabia: a survey by serologic and molecular methods. Am J Infect Control. 2004; 32(8):493-495.

15. Nie NH, Bent DH, Hull CH. SPSS: Statistical Package for the Social Sciences. New York, NY: McGraw-Hill; 1975.

16. Mohd Hanafiah K, Groeger J, Flaxman AD, Wiersma ST. Global epidemiology of hepatitis $\mathrm{C}$ virus infection: new estimates of age-specific antibody to HCV seroprevalence. Hepatology. 2013;57(4):1333-1342.

17. Ministry of Health of Kingdom of Bahrain. Basic Data on Infectious Diseases at Population Level. Bahrain: Ministry of Health; 2014.

18. Janahi EM, Al-Mannai M, Singh H, Jahromi MM. Distribution of hepatitis C virus genotypes in Bahrain. Hepatitis Monthly. 2015;15(12):e30300.

19. Hoofnagle JH. Hepatitis C: the clinical spectrum of disease. Hepatology. 1997;26(3 Suppl 1):15S-20S.

20. Chou R, Wasson N. Blood tests to diagnose fibrosis or cirrhosis in patients with chronic hepatitis $\mathrm{C}$ virus infection: a systematic review. Ann Intern Med. 2013;158(11):807-820.

21. Silini E, Bono F, Cividini A, et al. Differential distribution of hepatitis C virus genotypes in patients with and without liver function abnormalities. Hepatology. 1995;21(2):285-290.

22. Martinot-Peignoux M, Marcellin P, Gournay J, et al. Detection and quantitation of serum HCV-RNA by branched DNA amplification in anti-HCV positive blood donors. J Hepatol. 1994;20(5):676-678.

23. Gervais A, Martinot M, Boyer N, et al. Quantitation of hepatic hepatitis $\mathrm{C}$ virus RNA in patients with chronic hepatitis C. Relationship with severity of disease, viral genotype and response to treatment. J Hepatol. 2001;35(3):399-405.

24. Marcellin P, Asselah T, Boyer N. Fibrosis and disease progression in hepatitis C. Hepatology. 2002;36(5 Suppl 1):S47-S56.

25. Rothman AL, Morishima C, Bonkovsky HL, et al. Associations among clinical, immunological, and viral quasispecies measurements in advanced chronic hepatitis C. Hepatology. 2005;41(3):617-625.

26. Kowdley KV, Gordon SC, Reddy KR, et al; ION-3 Investigators. Ledipasvir and sofosbuvir for 8 or 12 weeks for chronic $\mathrm{HCV}$ without cirrhosis. N Engl J Med. 2014;370(20):1879-1888.
Hepatic Medicine: Evidence and Research

\section{Publish your work in this journal}

Hepatic Medicine: Evidence and Research is an international, peerreviewed, open access journal covering all aspects of adult and pediatric hepatology in the clinic and laboratory including the following topics: Pathology, pathophysiology of hepatic disease; Investigation and treatment of hepatic disease; Pharmacology of drugs used for the treatment

\section{Dovepress}

of hepatic disease. Issues of patient safety and quality of care will also be considered. The manuscript management system is completely online and includes a very quick and fair peer-review system, which is all easy to use. Visit http://www.dovepress.com/testimonials.php to read real quotes from published authors. 